\title{
SOBRE LA NARRATIVA DE ROSARIO CASTELLANOS Y LA ESPIRAL PARECE UN GÍRCULO DE A. LÓPEZ
}

La espiral parece un círculo de Aralia López González ${ }^{1}$ está dedicado al análisis de la narrativa de Rosario Castellanos (1924-1974), y más específicamente al de dos de sus obras: Oficio de tinieblas (1962) y Álbum de familia (1971). La selección de estas dos obras, entre otras de la misma autora, se funda en su carácter representativo respecto de las dos principales vertientes temáticas de la narradora mexicana: del indigenismo la primera, y del feminismo la segunda. Estas dos vertientes temáticas no son desde luego excluyentes entre sí. Nacieron entrelazadas desde Balún Canán (1957), pero fueron diferenciándose a partir del traslado de Rosario Castellanos de Chiapas, su estado natal, a la ciudad de México. Así, y mientras Oficio de tinieblas cierra el ciclo indigenista primero (Balún Canán, Ciudad Real y Oficio de tinieblas) dentro del cual venía gestándose la problemática femenina, Album de familia retoma esta última, centrándola en los conflictos entre tradición y modernidad, ya planteados en Los convidados de agosto (1964), trasladados esta vez al ámbito capitalino.

Como tesis doctoral en El Colegio de México, La espiral parece un círculo -imagen ésta que busca evocar la forma "apretada" de un desarrollo no lineal de la historia-, es también una propuesta de lectura teórica y metodológicamente fundamentada. El primer capítulo ( "De la crítica, la teoría y la metodología de análisis"') consiste en una exposición sucinta de la perspectiva crítica adoptada por la investigadora, de sus conceptos y sus reglas metodológicas. Dicha perspectiva se ofrece de entrada como una tentativa por conciliar dos "métodos" tradicionalmente separados y enfrentados entre sí: el inmanentista que, según T. Todorov, considera a la obra como "fin último"; y el sociológico - la obra

${ }^{1}$ UAM, México, 1991 (Textos y Contextos, 3). 
como "otra cosa", según el mismo Todorov-, que busca explicitar los nexos entre texto y contexto(s). Para tender un puente entre ambos métodos, Aralia López se vale de la noción goldmaniana de "visión del mundo", la cual asimila a la de "ideología" en los términos de Adolfo Sánchez Vázquez:

Ideología es: a) un conjunto de ideas acerca del mundo y la sociedad que b) responde a intereses, aspiraciones e ideales de una clase social y que c) guía y justifica un comportamiento práctico de los hombres acorde con esos intereses, aspiraciones e ideales ${ }^{2}$.

Sin embargo, y sólo para fines metodológicos, la investigadora conserva el término de "visión del mundo" para designar "el modo dominante de entender la realidad que organiza el texto", dejando el de "ideología" para referirse "a los sistemas de ideas provenientes del contexto social e histórico, exteriores a la obra" (p. 42). En otras palabras, la "visión del mundo" pertenece al texto y la "ideología" al contexto, lo que desde nuestro punto de vista debería poner en guardia contra equiparaciones apresuradas. Con hacer de la "visión del mundo" la forma literaria de la "ideología", no se hace sino postergar la conceptualización necesaria de las relaciones sumamente complejas entre dos órdenes de realidad distintos e irreductibles entre sí: lo "social" por un lado, y lo "textual" por otro.

En el orden de lo "social", entendido en términos marxistas ya que éste es el universo conceptual al que apela la investigadora, las "ideologías" y las "clases" (en plural ambas) no son realidades empíricas ni entidades nominales a las cuales se pudieran adscribir determinadas clases de "objetos". Son conceptos teóricos que, junto con otros a los cuales se encuentran indisolublemente ligados, permiten pensar relaciones y tendencias concretas implicadas en procesos socio-históricos (también en plural) a la vez solidarios y diferenciados entre sí. De modo que lo que en este marco define la existencia concreta de las clases y las ideologías son sus relaciones mutuas dentro del proceso concreto de que se trate. Relaciones mutuas que implican prácticas sociales diferenciadas, al mismo tiempo que la asignación de significaciones y valores distintos u opuestos a las prácticas propias y ajenas. En esto, la noción de contradicción, generalmente asignada a las relaciones entre clases, no es reductible a una simple oposición lógica, por cuanto

2 "La ideología de la neutralidad ideológica en las ciencias sociales", en La filosofía y las ciencias sociales, Grijalbo, México, 1976, p. 293. 
involucra situaciones y prácticas complejas junto con las significaciones y los valores asignados a unas y otras. Más que por un sistema de oposiciones lógicas, la contradicción se caracteriza entonces por una complejidad dinámica, cuya aprehensión requiere de instrumentos de formalización adecuados, y en todo caso sumamente variados y flexibles.

En cuanto a la realidad textual, que con toda razón Aralia López entiende como el resultado de una actividad a la vez social, individual y creadora (es decir, única e irrepetible), tiene, además de su inserción contradictoria en las relaciones sociales concretas en que se ejerce dicha actividad, una doble dimensión lingüístico-verbal y artística, cuya organización tiene sus reglas y sus leyes propias. Y éstas no son homogéneas entre sí, ni son del mismo orden de las que puedan estar rigiendo los procesos sociales en su conjunto. El principal escollo en el estudio de los fenómenos artísticos y culturales - que no existen efectivamente ni como "cosas en sí" ni como "otras cosas" - radica en la insuficiente discriminación entre órdenes y niveles de análisis. La confusión entre lo lingüístico-verbal, lo poético y lo social (o ideológico), y la proyección de los conceptos y las reglas de análisis de un orden o un plano sobre otro(s) conducen a una serie de traslapos que obstaculizan la cabal comprensión de sus relaciones mutuas.

En la medida en que, por la vía del "estructuralismo genético", la noción goldmaniana de "visión del mundo" puede efectivamente asimilarse a la de "ideología" (o al menos a una concepción sumamente discutible de lo que ha de entenderse por "ideología" en la teoría marxista), y puede empalmar al mismo tiempo por el sesgo de la noción de "coherencia" con una semántica estructural no menos discutible, contribuye de hecho a reforzar las rémoras que pesan sobre el estudio de los fenómenos literarios.

Sin embargo, cabe subrayar que si bien la publicación de $L a$ espiral parece un círculo data de 1991, su elaboración como tesis de doctorado se remonta a unos cuantos años atrás. Por lo mismo, la démarche teórico-metodológica que preside a dicha elaboración convierte al libro en buena muestra de un "momento teórico" y de sus dificultades. En efecto, en las formulaciones y dudas de la investigadora asoman aspectos que son precisamente los que fueron cobrando fuerza en las tendencias teóricas y críticas de la última década. Entre otros, los aspectos relacionados con la "intertextualidad", el "dialogismo"” o la "polifonía"; nociones és- 
tas que Aralia López entresaca del estudio de Julia Kristeva sobre El texto de la novela, el cual constituye a su vez una apropiación de los planteamientos de Mijaíl Bajtín (entonces aún no traducido ni al francés ni al español) en la perspectiva del estructuralismo francés representado a la sazón por el grupo Tel Quel. Por lo mismo, dichas nociones conservan en la exposición una dimensión puramente formal, sin alcanzar a cuestionar la noción goldmaniana de "coherencia" con las implicaciones metodológicas que de ella se derivan, ni a sentar el análisis de los textos seleccionados en torno a su poética concreta. Significativo es, a este respecto, el hecho de que la autora descarte el estudio de "lo grotesco como percepción de la realidad y tratamiento estético de la misma", en una nota de pie de página, como si "lo grotesco", con lo que implica de sarcasmo y "bi-vocalidad" o "dialogismo", no fuera parte de la modelización conjunta del mundo y el sujeto de la escritura en y por los lenguajes, (artísticos y no artísticos) que éste se apropia y relabora hasta conferirles sello y orientación propios.

Esta referencia a lo grotesco y a la poética concreta de los textos nos remite a otro de los postulados del enfoque de la investigación: el del carácter uniformemente "realista" de la narrativa de Rosario Castellanos, que la investigadora no problematiza. Este "realismo" puede sin duda definirse a partir de la orientación predominante del discurso literario hacia su objeto propio antes que hacia la "palabra ajena" y la autorreflexibilidad (en este caso, hacia la reconstitución del mundo indígena y ladino, o hacia el de la mujer); y, en consonancia con dicha orientación predominante, por la búsqueda de la "objetividad" ("veracidad" en los términos de Aralia López) en la reconstitución de dichos mundos. "Objetividad" o "veracidad" que la novela decimonónica europea solía encargar a un narrador "omnisciente", es decir exterior al universo narrado. Sin embargo, esta misma "objetividad" presupone la mise en ouvre de un conjunto de categorías analíticas y de formas de concebir el tiempo histórico y biográfico, el espacio social, los personajes, las relaciones entre éstos y la posición del narrador. Categorías y formas que, según Lukács, conducían -o habían de conducir- a "la configuración de personajes típicos en situaciones típicas", cuyo conjunto de relaciones dinámicas y contradictorias reproducían analógicamente la forma de las estructuras y las tendencias de los procesos sociales, mientras la "omnisciencia" del narrador era la fuente de aquel "exceso" o aquella "ironía" que según el mismo Lukács caracteriza la relación de aquél respecto de sus personajes. 
Ahora bien, la traslación de esta idea del realismo, concebida a partir de la novela decimonónica europea (y francesa en particular), al ámbito de la cultura y la novela hispanoamericanas, plantea una serie de dificultades, como lo atestigua el recurso de la crítica latinoamericana a denominaciones como "realismo social", "realismo mágico" o "real-maravilloso americano". Éstas son denominaciones que - de diversa manera- dan cuenta de modificaciones importantes y diversas de la poética "realista" en tierras americanas. Y ello en función de las profundas escisiones étnicas, sociales y culturales propias de naciones "a medio hacer", en donde las nociones de tiempo histórico y biográfico no tienen ni la misma forma ni el mismo arraigo que en la cultura europea, y en donde las formas de identidad subjetiva se elaboran en marcos que no son los que definen las instituciones relativamente estables del estado-nación. Es por lo tanto la misma noción de "personaje"', tal y como la hemos recibido de la crítica y la teoría europea o francesa, con sus formas específicas de individuación, la que está sujeta a revisión. Asimismo, y debido a las profundas escisiones a las que nos referíamos antes, el narrador de la novela hispanoamericana está lejos de constituir la entidad estable que se desprende de las nomenclaturas establecidas en función de otras realidades culturales y literarias. Más que "omnisciente", es un narrador que tiende a ser ubicuo, que multiplica los desplazamientos entre el "dentro" y el "fuera", y que junto con ello y en relación con los diversos ámbitos marcados por la heterogeneidad estructural, modifica constantemente sus identificaciones y sus distanciamientos: en él, las posiciones respectivas del "yo" y el "otro" se revierten a cada paso.

Oficio de tinieblas (1962) es sin duda una novela "indigenista" -y parcialmente "feminista" - por su tema. Sin embargo, participa mucho más del neo-indigenismo (a la manera de J. M. Arguedas) y del realismo mágico que del realismo social y el indigenismo de los años 20 y 30 . Busca reconstituir los mundos indígenas y ladino - junto con el de la(s) mujer(es) - con sus contradicciones y sus tendencias. Pero culturalmente, participa también de dos mundos en conflicto - el de la cultura local, autóctona y oral por un lado, y el de la cultura letrada, "universal" y escrita por otro-, en donde la mujer (como objeto y sujeto de la - narración) aún busca su voz propia -lo mismo que el indígena. En el plano de la composición, y como bien lo demuestra La espiral parece un círculo, ello da lugar al entrecruzamiento de dos tiempos distintos: el histórico, abierto y progresivo, y el mítico, 
repetitivo y circular. Pero en el doble plano de la composición (configuración de personajes) y el estilo (registros discursivos), se traduce al mismo tiempo en un cruce de perspectivas entre la configuración de "imágenes" (personajes "tipos" diversamente valorados por el narrador), y la asunción de resonancias, acentos, tonalidades y voces aún balbuceantes, que permean constantemente la voz enunciativa, confiriéndole aquella inestabilidad de la que hablábamos antes. Esta conjunción de imagen (orientación del discurso novelesco hacia su objeto propio) y $v o z$ (orientación hacia una "palabra ajena" que rebasa ampliamente el ámbito de la "intertextualidad" rastreada por la investigadora para abarcar el de la palabra viva, no escrita), conlleva el que la significación de Oficio de tinieblas no se pueda desprender sólo de la estructura del enunciado y de la valoración, supuestamente uniforme, de sus elementos por parte del narrador (¿o la narradora?). En la organización de la significación artística intervienen también las diversas relaciones inestables y ambiguas, que mantiene la voz enunciativa respecto de los múltiples lenguajes movilizados y de los contenidos que éstos formalizan. En otras palabras, estas relaciones complejas constituyen un indicio recurrente de la tensión existente entre el prurito de objetividad que descansa en un narrador sólo parcialmente "externo", y la inmersión de éste en los conflictos estilísticos y culturales que provienen de la heterogeneidad y las escisiones socioculturales propias de su referente.

Esta tensión en la modelización artística conjunta del sujeto y el objeto de la narración, y el inacabamiento semántico del texto que de ello se deriva, pone de manifiesto el inconveniente de postular el que ambos (sujeto y objeto) pudieran preexistir al proceso de la escritura, bajo la forma de una "ideología" a la que la "visión del mundo" se encargaría de conferir forma artística.

Por otra parte, los cuentos que integran Álbum de familia (1971) tampoco obedecen a la misma poética que Oficio de tinieblas. "Lección de cocina" está construido con base en un diálogo interno que estiliza y parodia discursos muy diversos, que tienen por función no la de reconstruir desde fuera un sistema de contradicciones sociales "objetivas" en las que estuviera inserta la mujer, sino la de aprehender desde dentro, y mediante la convención de la narración en primera persona, las veleidades y subterfugios de una identidad en conflicto que brega por asumirse a sí misma como persona. Que esos discursos hagan referencia a la "condición femenina", es decir a papeles y normas socialmente definidos, no cabe duda. Pero no es éste el objeto de la representación, sino la 
inestabilidad de identificaciones sucesivas y múltiples que revierten constantemente los papeles del "yo" y el "otro" o "lo otro", y que en ausencia de cualquier opción definida ("el diagnóstico es fácil, ¿ pero qué consecuencias acarrearía asumirlo?'), conducen a la veleidosa afirmación de una "autenticidad" que no halla por lo pronto más sustancia que la corporeidad femenina - corporeidad que, por cierto, ironizan en otro nivel las metamorfosis de la carne puesta en el asador.

La relativización de los múltiples discursos movilizados (y de los papeles ligados a ellos) mediante los constantes desplazamientos subjetivos de la narradora y protagonista, el cierre final en un punto muerto aparejado con el "Y sin embargo..." con que concluye (o vuelve a abrirse) el relato, y la ironía que recae sobre el "trozo de carne" (del asador, de la mujer, pero también del marido), no autorizan a nuestro modo de ver el que se privilegie uno de esos discursos - huellas de discursos - para hacerlo coincidir con el punto de vista (la "ideología" o la "visión del mundo") de Rosario Castellanos (por ejemplo el existencialismo, posiblemente aludido por la introducción de la noción de "autenticidad"). Esta noción de "autenticidad" no representa aquí sino una de las formulaciones de aquella virtualidad corporeizada —afirmación y negación juntas-, sujeta al desgaste del tiempo (el fuego) mientras la mujer no se asume a sí misma como proceso. Lo que en otro momento de sus disquisiciones, la misma protagonista enuncia bajo la forma de que "la materia es energía, o como se llame". Pero este otro enunciado, barajado entre muchos, tampoco hace del relato la mise en forme de concepciones acordes con la física cuántica.

El objeto modelizado aquí - la identidad virtual de la mujeraparece como propiamente inasible, y como tal lo asume el sujeto de la escritura: mediante la asunción de una forma esencialmente dialógica, irónica y paródica, que excluye cualquier solución o enjuiciamiento a priori por parte de la autora. El punto de vista de Rosario Castellanos es todo menos unívoco.

Forzada también nos parece la interpretación que propone la autora de "Domingo" a la luz del existencialismo sartreano, supuestamente introducido por un narrador externo y omnisciente que, además de organizar el tiempo y el espacio del relato en torno a una oposición entre el "ser" y el "estar", estuviera enjuiciando la "doble enajenación pequeño-burguesa" de su protagonista. No hay en el texto huella alguna de tal enjuiciamiento. Hay si, por parte del narrador, la delimitación de un espacio social pre- 
ciso - el de unas capas medias acomodadas que mantienen vínculos ambiguos con los negocios, el ejército y la creación intelectual o artística- y la (re)presentación de las relaciones no menos ambiguas que mantienen entre sí los personajes que lo configuran. El relato se centra en torno al desgastado matrimonio anfitrión, desde la perspectiva de la mujer y los distintos papeles que le toca asumir. En esto, la función del narrador en tercera persona es ante todo la de un metteur en scène que distribuye espacios y papeles. Y no sólo porque el relato tenga efectivamente mucho de teatralización de relaciones entre personajes ellos mismos teatrales, sino porque su concepción artística de conjunto es eminentemente cinematográfica: la mirada (o la cámara) es la que lo organiza en una sucesión de encuadres, planos, secuencias, travellings, flash-backs, voz en "off", etc. Estos procedimientos cinematográficos son los que permiten un desdoblamiento parcial entre la mirada del "narrador" y la de su protagonista, ella misma "desdoblada" entre "las apariencias ofrecidas al consumo del público" - la representación de los papeles domésticos y sociales-y la "verdad íntima", cuidadosamente resguardada de la mirada ajena. Con base en los múltiples desplazamientos de las miradas entre lo "externo" y lo "interno" y en la homofonía de la voz del narrador con respecto a la de Edith, el relato transcurre en torno a un planteamiento sutil: el difícil equilibrio de la identidad de su protagonista. Libertad aprisionada - como la de Rafael, el autor del retrato que la "expone en su intimidad más honda" - , esta identidad se encuentra vinculada con y afianzada en la propia realización artística, prolongación del amor y la gratitud por el descubrimiento de la sensualidad. Al inicio del relato, aquel retrato no parece guardar "su equilibrio perfecto. Edith se acercó a él, lo movió un poco hacia la izquierda, hacia la derecha y se retiró para contemplar los resultados. Casi imperceptibles, pero suficientes para dejar satisfechos sus escrúpulos"'3. Al final, y transcurrido el día domingo que pone Edith a prueba, el narrador concluye junto con ella y la "mirada escrutadora" que la define desde la primera frase del relato:

Edith observaba las evoluciones de Octavio, su talentoso y sabio despliegue de las plumas de su cola de pavo real ante los ajos ingenuos y deslumbrados de Hildegard. Y vio a Hugo mordiéndose las uñas de impotencia. Y a Vicente riendo por lo bajo, en espera de su opor-

${ }^{3}$ R. Castellanos, Álbum de familia, J. Mortiz, México, 1971, p. 23. Me baso en esta ed.; en adelante sólo indicaré la página entre paréntesis. 
tunidad. Se vio a sí misma excluida de la intimidad de Carlos y Lucrecia, del dolor de Jorge, del juego de los otros. Se vio a sí misma, borrada por la ausencia de Rafael y un aire de decepción estuvo a punto de ensombrecerle el rostro. Pero recordó la tela comenzada en su estudio, el roce peculiar del pantalón de pana contra sus piernas; el sweater viejo, tan natural como una segunda piel. Lunes. Ahora recordaba, además, que había citado al jardinero. Inspeccionarían juntos ese macizo de hortensias que no se quería dar bien (p. 46).

Sugerida en filigrana desde los primeros párrafos del relato, la poética del texto no conduce hacia un planteamiento y una solución existencialistas, sino una vez más hacia la modelización artística de una problemática abierta, en donde la identidad dividida, inestable y porfiada de la mujer busca definirse desde dentro y en contraposición con los papeles que tiende a asignarle la forma - tradicional o moderna- de las estructuras y las relaciones sociales imperantes.

Mucho más logrado es, a nuestro modo de ver, el análisis de "Cabecita blanca", cuya ironía para con el estereotipo de la familia y la mujer tradicionales (pero moldeadas también por los medios de comunicación de masas) pone justamente de relieve Aralia López. El estudio fino y detenido que nos ofrece rebasa ampliamente el esquema de oposiciones binarias con el cual sintetiza al final, como en los demás casos, los resultados de su investigación acerca de la significación del texto. Esta repartición binaria de los contenidos contraviene el funcionamiento de la ironía y el análisis de sus mecanismos, sin embargo tan bien advertidos por la investigadora. De haber colocado el objeto de su análisis en la sistematización de estos mecanismos, renunciando al intento de $f i$ jar contenidos a los cuales el texto alude como modo específico de ir configurando su significación, Aralia hubiera podido lograr aquí un estudio redondo de este tercer relato de Rosario Castellanos.

En cuanto a la interpretación del último de los relatos -el que da su nombre al volumen- resulta nuevamente forzada por la extrapolación, en más de una ocasión excesiva o arbitraria, de los enunciados a cargo de los diferentes personajes del drama, entre trágico y grotesco, que se juega en torno a la persona y la figura de Matilde Casanova. El apego de la investigadora a ciertos supuestos del existencialismo por un lado y al sistema de oposiciones binarias por otro, no le permite reparar en las diferencias de jerarquización entre enunciados estilizados y parodiados, ni en la evolución del drama, en particular del lugar y papel de Victo- 
ria, la secretaria aparentemente sumisa y abnegada. La interpretación tiende entonces hacia una nivelación de los diferentes enunciados y hacia la construcción de una argumentación demasiado lineal que busca oponer dos mundos (el de los hombres, "ellos", y el de las mujeres) y dos concepciones de la poesía (la "metafísica" y la "realista").

Sin embargo, a lo que asisten Cecilia y Susana desde su escondite primero y desde su marginalidad generacional luego, no es exactamente a eso, sino a la exhibición y al disfraz de las contradicciones en las que se hallan envueltas las mujeres que han accedido - o pretenden acceder - a la vida intelectual o a la creación artística, y sobre todo, a la lucha cruel y despiadada que desatan entre ellas las ambiciones y la fama literarias. Lucha cruel y despiadada que no es otra cosa que la parodia de las relaciones que imperan por un lado en el mundo artístico y político en su conjunto - como lo resalta desde el inicio el tenso diálogo entre Victoria y la periodista-, y por el otro entre el lombre y la mujer en tantas parejas "intelectuales". Relaciones éstas que reproducen a pesar suyo Matilde y Victoria, y cuyas formas de dominación resultan menos unívocas de lo que podría pensarse, como se desprende de las posteriores "confesiones" de Victoria.

El objeto de la focalización en "Álbum de familia" y el efecto catártico que busca producir en sus lectoras (prefiguradas por $\mathrm{Su}$ sana y/o Cecilia), la mezcla de lo trágico y lo grotesco, no apuntan hacia la problematización o la confirmación de determinadas ideas acerca del ser humano o las formas de la poesía y su función social. Cuestionan la dudosa interiorización, por parte de las mujeres, de actitudes vitales equívocas y (auto) destructivas (que, desde luego, involucran también una relación con el quehacer literario). Aunque "abierto" en cuanto a las opciones vitales y poéticas posibles, el final del relato resulta bastante claro: de lo que se trata, una vez más, es de devolver las mujeres a sí mismas, a la aceptación lúcida de su "desvalimiento", de aquella "herida invisible que nunca abrió los labios", la cual no es en fin de cuentas sino la irrenunciable parte de soledad que, junto con su parte de libertad, halla a su paso cualquier ser humano dispuesto a asumir su propio "centro de gravitación". Esto mismo que descubre Cecilia de regreso al hotel, al encontrarse con la carta de despedida de Ramón, con

aquellos párrafos escritos con la letra que conocía tan bien y que se eslabonaban en frases tiernamente irónicas, reclamo y rechazo 
a la vez, equidistancia, en suma [...] Estrujando el papel entre las manos Cecilia deseó ser él y partir, lejos, lejos a cualquier parte y no regresar nunca. Pero Cecilia no era él era nada más ella y esta certidumbre le produjo una tristeza que no acertó a ocultar a Susana. Pero a su interrogatorio ¿solícito? ¿impertinente? ¿rutinario? no respondió más que como por enigmas, afirmando que lo que la había deprimido y hasta horrorizado era, quizá, haber descubierto su centro de gravitación (p. 154).

¿Eco de existencialismo? Tal vez. Aunque, antes que una filósofa o una “ideóloga” hay en Rosario Castellanos una moralista más preocupada por devolverle a la mujer su propia imagen cuestionándola desde la subjetividad femenina misma y sin olvidar por ello las condiciones sociales y culturales que contribuyen -o contribuyeron - a moldearla, que por reconstruir y denunciar la "'dominación masculina". De ahí que la exploración de los múltiples registros de la ironía sea el fundamento mismo de una poética destinada a cumplir con una función catártica.

Nuestras discrepancias con los análisis que de Oficio de tinieblas y Álbum de familia ofrece Aralia López en La espiral parece un círculo, se sitúan entonces y fundamentalmente en una serie de desplazamientos de los objetivos de la función crítica; desplazamientos que, a nuestro modo de ver, llegan incluso a sesgar las posibles interpretaciones de la(s) significación(es) de los textos. Centrar el análisis en la "visión del mundo" del autor -entendida ésta en un sentido próximo al que la investigadora asigna a la "ideología" - sin pasar por la poética concreta de los obras estudiadas, o mejor dicho sustituyendo el análisis poético por otro de carácter lógico-formal, entraña una serie de confusiones que tiene repercusiones importantes no sólo en la interpretación de los textos, sino también en el establecimiento de sus posibles vínculos con la historia literaria primero, y con la historia social y cultural después. En el plano de la interpretación, lleva a una nivelación indebida de los contenidos ideológico-culturales y discursivos movilizados (la materia preexistente al momento de la escritura) con la forma que los organiza, jerarquiza y relabora artísticamente con miras a la producción de efectos específicos. Ciertamente, es labor de la crítica hacer explícitos los múltiples aspectos del sustrato ideológico-cultural que vuelve posible una escritura dada. Y en este sentido, La espiral parece un círculo proporciona al lector una información amplia y valiosa. Pero estos "contenidos", que sin duda dejan importantes huellas en los planos estilístico y composicional del texto, no representan a fin de cuentas 
sino la condición de su posibilidad como texto artístico. En éste, reciben formas de organización específicas - mas no desligadas de su materialidad lingüístico-discursiva, ideológica y cultural-, que convierten al texto en el lugar de una tensión entre su tendencia a la autonomía y su tendencia a la apertura sobre los diversos lenguajes sociales - literarios o no- y sobre la historia en su conjunto. De modo que la significación artística no es reductible a los contenidos movilizados (proviene del complejo sistema de relaciones que establece entre ellos), ni los lazos que mantiene el texto con sus contextos (de escritura y de lectura) pueden concebirse como bi-unívocos por la vía de una identificación de la "visión del mundo" interna con alguna "ideología" externa. En realidad el texto vive (y las sucesivas y diversas lecturas de las que es objeto así lo demuestran) de sus relaciones múltiples e inestables con el horizonte, asimismo inestable, de la cultura en devenir. Y, en esto, es su poética concreta la que fija límites a sus posibles (re)interpretaciones.

Fijar el sentido (o la significación) confiriéndole al texto una lógica que no es la suya (la sistematicidad de una "ideología") no puede ser entonces el objeto del discurso crítico. A partir de la explicitación del sustrato que lo hace posible, su función consiste más bien en dar cuenta de las particularidades del lenguaje artístico en el cual se halla cifrado, contribuyendo así a la formación estética de sus lectores.

En el caso concreto de la narrativa de Rosario Castellanos, el problema se situaba, a nuestro modo de ver, en la problematización de lo que Aralia López da por evidente: el carácter supuestamente "realista" de la obra de la narradora mexicana. Atribuir a Oficio de tinieblas y Álbum de familia una dimensión realista, sin interrogarse acerca de los modos de concebir y figurar "lo real" en dichos textos, no deja de resultar anacrónico, e impide pensar el lugar y papel de Rosario Castellanos en el proceso, complejo y diferenciado, de la narrativa mexicana. No creemos por nuestra parte que este lugar y papel pueda definirse por la simple asunción de una temática femenina o feminista, aparejada con una defensa del realismo en literatura. Parecería pasar más bien por la búsqueda común a muchos narradores mexicanos e hispanoamericanos de la época, de soluciones artísticas a un problema de dialogismo social y cultural aún incipiente (o en todo caso difícil), y por una interrogación acerca de las formas de constitución de las identidades subjetivas - femeninas o no- en este mismo marco. 
De cualquier forma, el debate en torno a las contribuciones de Rosario Castellanos a la narrativa mexicana y las modalidades del género narrativo sigue abierto. Y, en la continuación de este debate, La espiral parece un círculo de Aralia López González tendrá que seguir presente.

Françoise Perus Universidad Nacional Autónoma de México 